\title{
Mining Flickr: a method for expanding the known distribution of invasive species
}

\author{
STEVEN J. R. ALLAIN \\ Cambridgeshire and Peterborough Amphibian and Reptile Group \\ Author e-mail: steveallain@live.co.uk
}

\begin{abstract}
It is important to map invasive species in order to demonstrate their rate of spread and current distribution. Most recording schemes rely on opportunistic sightings and awareness to collect and gather data. Mining data from online social media and other data sharing platforms has become more prevalent in recent years as increasing numbers of users share more information. In this study, sightings from the image sharing platform Flickr were compared with the records submitted to the national recording scheme Record Pool. This study was completed to determine whether or not there was a significant difference between these two as sources for sightings of fresh water turtles across the UK.
\end{abstract}

\section{INTRODUCTION}

$F_{\text {resiser }}$ esh water turtles as a group are not native to the UK, however they were once part of the British herpetofauna assemblage during the Holocene period (Sommer et al., 2007). In past decades, several turtle species have been introduced into ponds and waterways throughout the country following the Teenage Mutant Hero Turtle craze of the late 1980s and early 1990s (Beebee \& Griffiths, 2000). Several species were imported, mainly from North America, where they were bred in vast quantities specifically for the pet trade (Warwick, 1986). By far the most common species was the red-eared slider (Trachemys scripta elegans), which under the right conditions can live for 40 years and reach a mature size of $280 \mathrm{~mm}$ in just a few years (Wareham, 2008). Due to their voracious appetite and rapid growth spurts, red-eared sliders quickly outgrow the care of their owners and unfortunately many were then released into the local environment. Fresh water turtles are now widespread across the UK (Beebee \& Griffiths, 2000), with the red-eared slider being the most frequently recorded species, perhaps due to its popularity as a pet (Langton et al., 2011). Other species such as the yellow-bellied slider ( $T$. scripta scripta) and map turtle (Graptemys geographica) were also common pets and can be still be encountered in the wild.

Thankfully due to our much colder climate, these introduced turtles are unable to breed (Beebee \& Griffiths, 2000). This situation could change as our climate warms and certainly elsewhere in Europe red-eared sliders do breed and have started to compete with native turtle species (PerezSantigosa et al., 2008; Polo-Cavia et al., 2011). In the UK, it is illegal to release turtles into the wild under the regulations of the 1981 Wildlife and Countryside Act. Since 1997, the trade in Europe of fresh water turtles imported from the USA, such as the red-eared slider and the painted turtle (Chrysemys picta), has been restricted following the introduction of Council Regulation 338/97/EC, resulting in a reduction of American species for sale in pet shops. The introduction of non-native species to an ecosystem usually causes some level of disruption, however the effects of turtle introductions into the UK remain largely unknown.

Fresh water turtles are often quite conspicuous in the areas where they have been introduced, basking on logs or banks along canals and lakes etc. (Beebee \& Griffiths, 2000). For this reason, they are often photographed by members of the public as they may either be concerned or excited about their sightings. Sometimes these images are uploaded to online file-sharing platforms that can then be mined, and later analysed (Daume, 2016). The records of different animals/plants submitted to various recording schemes are opportunistic in nature and only offer a snapshot at a single moment in time, much like a photograph. This being the case, the potential for the photography sharing platform Flickr (https://www.flickr.com/) was explored as a novel source of verifiable records of turtle sightings across the UK. These records were then compared with the data submitted to Record Pool to determine whether or not there was a significantly greater number of records held on Flickr and whether they differed much in their locations.

\section{METHODS}

In order to retrieve suitable images, Flickr was searched using a number of different search terms (see Table 1 for a small example of these) for relevant photos of fresh water turtles. When an appropriate photo was found during a search, the species was identified and recorded along with the number of specimens and their location (including both the county and nearest town/city). If the photos were geo-tagged then this information was used to geo-reference the water body where the turtles were photographed; other photo metadata such as the date the photo was taken were also recorded. For photos that were not geo-tagged, the location information within the description of the photo was relied upon. With this information, the centre of the water body within the given area was taken as an approximate location. For locations with more than one water body, the midpoint between them was treated as the location. This was completed using Grid 
Table 1. Some of the search terms used during the study showing the total number of results from the whole Flickr database and the total number from within the search period. Note the diminishing number of results as search terms become more specific, the example used was typical of searching for red-eared slider photos.

\begin{tabular}{|lcc|}
\hline Search term & Total results & Results within 2008-18 \\
\hline Terrapin UK & 948 & 870 \\
Terrapin Britain & 700 & 636 \\
Pond terrapin UK & 130 & 120 \\
Pond terrapin Britain & 93 & 84 \\
Red-eared slider UK & 66 & 61 \\
Red-eared slider Britain & 49 & 17 \\
\hline
\end{tabular}

Reference Finder (https://gridreferencefinder.com/) was used to provide both the coordinates needed to define the locality as well as its grid reference (to six figures) which gives an accuracy within 100 metres. In the event that a defined place name was not available within the metadata or the description of the photo, the photographer was contacted to help provide further information. Care was taken to ensure that only feral turtles were included in the analysis; those photographed in zoos or wildlife parks were excluded.

\section{RESULTS}

In the period 2008 and 2018, a total of 258 fresh water turtle sightings (of 5 species, Table 2) were detected through Flickr compared with only 86 submitted to Record Pool in the same period. The mean annual number of sightings from Flickr was 23.45 and 7.8 from Record Pool. When comparing the data between years (Fig. 1), there were significantly more data gathered from Flickr than Record Pool (paired $t$-test, $t$ $=5.2002, d f=10, p=0.0004)$. There was also a significant difference in the number of records collected from both sources between the different months of the year (paired $t$-test, $t=3.6193, d f=11, p=0.004$ ) and the peak number of counts from both systems was in May (Fig. 2).

The data submitted to Record Pool has been slowly increasing through time (Fig. 1) whereas the number of sightings available through Flickr has been more consistent over time (except for 2014). No records were submitted to Record Pool in 2015 whereas there were 27 sightings detected through Flickr. In 2017 and 2018 there was a distinct increase in the number of photos of turtles submitted to Flickr. Despite these differences between the two systems, they show broadly similar geographical coverage (Fig. 3).

\section{DISCUSSION}

The total number of fresh water turtle sightings within the UK recorded on Flickr from 2008 to 2018 was significantly greater than those submitted to Record Pool in the same period. This clearly demonstrates the potential of photo sharing platforms such as Flickr as a source of faunal records. Researchers have already successfully used social media to investigate the trade in turtles in Vietnam (Van et al., 2019) and to even evaluate which species of amphibians are most often kept as pets (Measey et al., 2019). Despite the fact

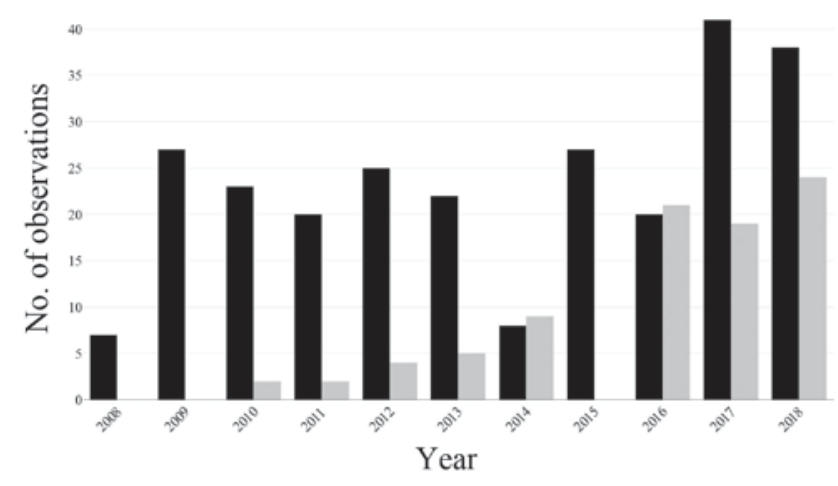

Figure 1. A graph comparing the frequency of turtle sightings from Flickr (in black) with Record Pool (in grey) from within the search period, $2008-2018$

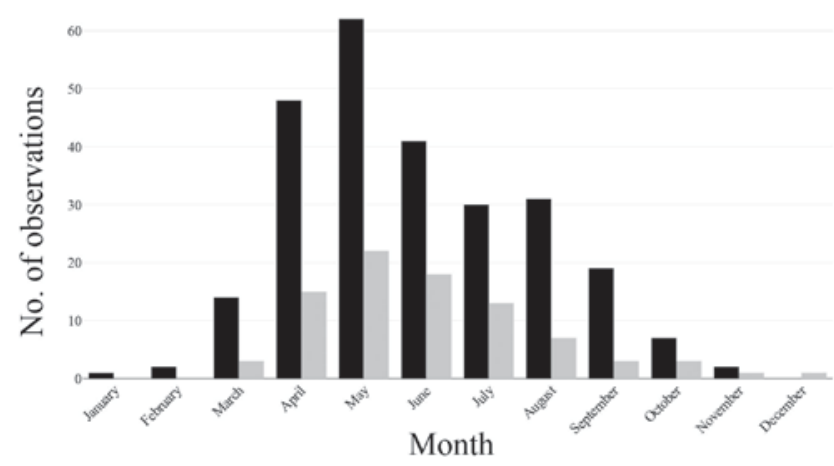

Figure 2. A graph comparing the frequency of monthly turtle sightings from Flickr (in black) with Record Pool (in grey) for the period 2008 - 2018. Both systems show a peak of observations in May.

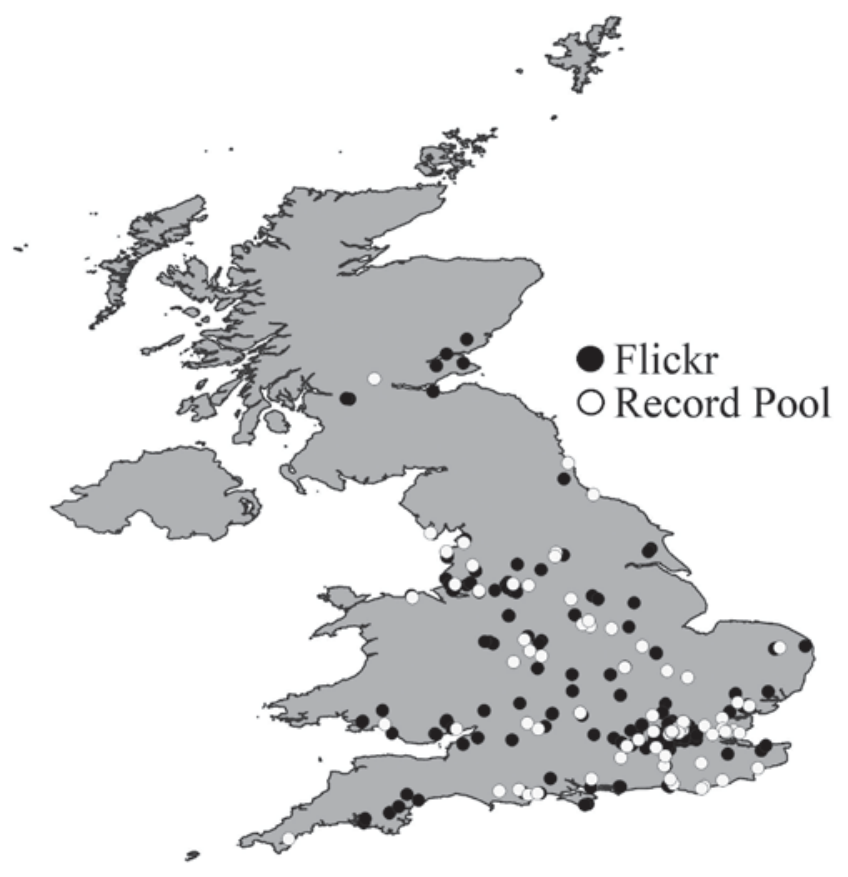

Figure 3. A map comparing the distribution of sightings across all species from Flickr (black) and Record Pool (white) 
Table 2. The species identified during the intensive Flickr search and the number of sightings associated with each species.

\begin{tabular}{|llc|}
\hline Common name & Scientific name & $\begin{array}{c}\text { Number of } \\
\text { sightings }\end{array}$ \\
\hline Red-eared slider & Trachemys scripta elegans & 163 \\
Yellow-bellied slider & Trachemys scripta scripta & 89 \\
Map turtle & Graptemys geographica & 4 \\
European pond turtle & Emys orbicularis & 1 \\
Common snapping turtle & Chelydra serpentina & 1 \\
\hline
\end{tabular}

that the searches were completed manually, the data was collected in a relatively short time. The advantage of Flickr over Record Pool is that as every record has a photo, you can identify the species and verify it. Flickr also preserves the photo metadata which can be used to determine when a photo was taken, and in some cases even where. For this project, all of the records submitted to Record Pool were assumed to be correct although there wasn't always the same species-level detail available as there was on Flickr.

Fresh water turtles are most active between April and October (Inns, 2009) although they may be seen throughout the year (Fig. 1). The month with the most sightings from both datasets was May, indicating that this may be an ideal time to implement turtle surveys across the country. The effects of these turtles on British ecosystems are not currently understood but may be significant as they are known to be voracious predators potentially consuming ducklings, fish, amphibians and other wildlife (Beebee \& Griffiths, 2000). Further research is needed to confirm the diet of feral turtles as well as their interactions with other species. Fresh water turtles have been introduced into a number of other countries around the world where they have impacted native fresh water turtle species (Ramsey et al., 2007). Here in the UK though, the exact distribution of the turtles is not known and consequently a current citizen science project, the 'Turtle Tally' initiated by Hadlow College and the British Herpetological Society in early 2019, is seeking to fill this gap. The information gathered may be used to help manage feral turtles if later research confirms that they have a negative impact on local ecosystems.

It is important to consider a number of different search terms when searching Flickr as not every photo will have the correct title or the appropriate tags. The careful choice of terms is also important and in the current study the use of 'turtle UK' rather than just 'terrapin' yielded over 5,600 results which within this project would have created an excessive workload. For the future this could potentially be tackled by replacing manual searches with machine learning to automate the process. When using search terms, broad terms as well as specific ones should be used as there is a trend towards fewer results when using more specific search terms (Table 1). The number of records submitted to Record Pool has been slowly increasing since its launch (Fig. 2) whereas Flickr has been more consistent over time although there has been an substantial increase in sightings submitted to Flickr in the past two years (2017-2018) but this may simply be linked to an increase in the number of users rather than an increase in turtle numbers.
There is a large degree of overlap in the wider geographical distribution of sightings between Flickr and Record Pool (Fig. 3 ) which is quite striking given the large difference between the size of the two data sets. Further analysis is required to determine how closely or by how much the two implied turtle distributions differ but at least in the metropolitan areas such as London and Manchester, where there are both more people and likely more turtles as a consequence, there is relatively little overlap between the records. Most sightings are from the southern half of England with sightings becoming rarer as you get closer to the Scottish border, although there are a small number of sightings from both sources within Scotland. It has previously been stated that within Scotland fresh water turtles are only rarely encountered (Mclnery et al., 2016), this is confirmed by the current data and probably relates to a poor climate for turtles. There are no sightings of them in the Scottish Highlands but this is likely linked to human distribution with fewer people owning freshwater turtles and fewer people releasing them. There are no reported turtle sightings for Northern Ireland which indicates that further surveys are needed to discover whether or not this reflects reality.

Flickr has helped to provide a vast number of additional records that have contributed to a much more detailed distribution mapping for turtles within the UK when combined with Record Pool data. In order to gain more consistency in the future, outreach should target the sighting of turtles and how to record them properly.

By using data acquired by mining social media it may be possible to make distribution maps of any species more comprehensive (not just fresh water turtles). There is also the need to integrate data uploaded to social media sites with conventional faunal recording systems, such as Record Pool, so that the information obtained can be stored in a common repository. Organisations such as the Amphibian and Reptile Groups UK (ARG UK) and the Non Native Species Secretariat (NNSS) could then use this data for follow-up surveys if they see fit to confirm the presence of alien species. The current social media platforms available for the kind of mining described above include Flickr, Twitter and Facebook.

\section{ACKNOWLEDGEMENTS}

I would like to thank Angela Julian from ARG UK for sharing the appropriate data from Record Pool that helped to facilitate this project.

\section{REFERENCES}

Beebee, T. J. C. \& Griffiths, R. A. (2000). Amphibians and Reptiles. HarperCollins, London. $270 \mathrm{pp}$.

Daume, S. (2016). Mining Twitter to monitor invasive alien species-An analytical framework and sample information topologies. Ecological Informatics 31: 70-82.

Inns, H. (2009). Britain's reptiles and amphibians: A guide to the reptiles and amphibians of Great Britain, Ireland and the Channel Islands. WildGuides. $164 \mathrm{pp}$.

Langton, T. E. S., Atkins, W. \& Herbert, C. (2011). On the distribution, ecology and management of non-native reptiles and amphibians in the London Area. Part 
1. Distribution and predator/prey impacts. London Naturalist 90: 83-155.

Mclnerny, C. J., Minting, P. J., Cathrine, C. \& O’Brien, D. (2016). The Amphibians and Reptiles of Scotland. Glasgow Natural History Society. 312 pp.

Measey, J., Basson, A., Rebelo, A. D., Vimercati, G., Louw, M. \& Mohanty, N. P. (2019). Why have a pet amphibian? Insights from YouTube. Frontiers in Ecology and Evolution 7: 52.

Perez-Santigosa, N., Diaz-Paniagua, C. \& Hidalgo-Vila, J. (2008). The reproductive ecology of exotic Trachemys scripta elegans in an invaded area of southern Europe. Aquatic Conservation 18: 1302-1310.

Polo-Cavia, N., López, P. \& Martín, J. (2011). Aggressive interactions during feeding between native and invasive freshwater turtles. Biological Invasions 13: 1387-1396.

Ramsay, N. F., Ng, P. K. A., O’Riordan, R. M. \& Chou, L. M. (2007). The red-eared slider (Trachemys scripta elegans) in Asia: a review. In Biological invaders in inland waters: profiles, distribution, and threats. (pp. 161-174). Springer, Dordrecht.
Sommer, R. S., Persson, A., Wieseke, N. \& Fritz, U. (2007). Holocene recolonization and extinction of the pond turtle, Emys orbicularis (L., 1758), in Europe. Quaternary Science Reviews 26: 3099-3107.

Wareham, D. C. (2008). The Reptiles and Amphibians of Dorset. British Herpetological Society. 120 pp.

Warwick, C. (1986). Red-eared terrapin farms and conservation. Oryx 20: 237-240.

Van, T. P., Luu, V. Q., Tien, T. V., Leprince, B., Khanh, L. T. T. \& Luiselli, L. (2019). Longitudinal monitoring of turtle trade through Facebook in Vietnam. The Herpetological Journal 29: 48-56.

Accepted: 29 April 2019 